\title{
Surface Tension and Viscosity of the Ni-Based Superalloys LEK94 and CMSX-10 Measured by the Oscillating Drop Method on Board a Parabolic Flight

\author{
RAINER K. WUNDERLICH, HANS-JÖRG FECHT, and GEORG LOHÖFER
}

\begin{abstract}
The surface tension and viscosity of the Ni-based superalloys LEK94 and CMSX-10 were measured by the oscillating drop method in a containerless electromagnetic processing device on board a parabolic flight airplane. Surface oscillations were recorded by 150 and $200 \mathrm{~Hz}$ frame rate digital cameras positioned in two perpendicular directions and by the inductive coupling between the oscillating sample surface and the oscillating circuit of the radio frequency heating and positioning generator. The surface tension as a function of temperature of LEK94 and CMSX-10 was obtained as $\sigma(T)=1.73-4.51 \times 10^{-4}\left[T-1656 \mathrm{~K}\left(1383^{\circ} \mathrm{C}\right)\right] \mathrm{Nm}^{-1}$ and $\sigma(T)$ $=1.71-5.80 \times 10^{-4}\left[\left(T-1683 \mathrm{~K}\left(1410^{\circ} \mathrm{C}\right)\right] \mathrm{Nm}^{-1}\right.$, respectively. The viscosity at the liquidus temperatures as 9.8 and $7.8 \mathrm{mPa} . \mathrm{s}$, respectively. In addition, some basic thermophysical properties such as solidus and liquidus temperatures, densities at room temperature, and thermal expansion in the solid phase are reported.
\end{abstract}

DOI: $10.1007 / \mathrm{s} 11663-016-0847-y$

(C) The Author(s) 2016. This article is published with open access at Springerlink.com

\section{INTRODUCTION}

Ni-BASED superalloys are well established high-temperature materials. They are based on a two-phase mixture of the ordered and disordered intermetallic $\mathrm{Ni}_{3} \mathrm{Al}$ phases with additions of transition metals like $\mathrm{Ti}, \mathrm{Cr}, \mathrm{Co}$; refractory elements like W, Mo, Ta; and elements of the Pt group like Re. ${ }^{[1,2]}$ The typical $\mathrm{Ni}$ concentration is between 56 and 68 at. pct; $\mathrm{Al}$ concentration is between 8 and 16 at. pct; the refractory element concentration is between 3 and 8 at. pct; and Re concentration is in the range of 1 to 7 at. pct. The main application is for energy generation in land-based turbines and in the high-pressure section of jet engine turbines. One goal of current alloy development is an increase in the working temperature combined with high fatigue and creep resistance.

The main production route is casting of turbine blades with directional single-crystalline solidification followed by extensive solution and annealing heat treatments to achieve the desired element distribution and microstructure. Optimization of production technology and of final product quality requires knowledge of the thermophysical properties in the high-temperature solid and in the liquid phase. Important thermophysical properties for a first-order casting simulation ${ }^{[3,4]}$ are solidus and liquidus

RAINER K. WUNDERLICH, Senior Research Scientist, and HANS-JÖRG FECHT, Director, are with the Institute for Micro and Nanomaterials, Ulm University, Albert-Einstein-Alle 47,D-89081, Ulm, Germany. Contact e-mail: rainer.wunderlich@uni-ulm.de GEORG LOHOFER, Senior Research Scientist, is with the Institut für Materialphysik im Weltraum, Deutsches Zentrum Luft- und Raumfahrt, DLR, Köln, Germany.

Manuscript submitted January 29, 2016.

Article published online November 9, 2016. temperatures, fraction solid-liquid, specific heat capacity, density, thermal conductivity, viscosity, and surface tension. ${ }^{[5]}$ Knowledge of the surface tension and viscosity as a function of temperature are required for the modeling of surface and gravity driven flows, and together with the density and specific heat capacity as a function of temperature for the modeling of convective heat transfer. Other important issues are form filling in near net shape castings, and the prediction of defects such as bubble formation. ${ }^{[6]}$

Due to their technical importance, continuous efforts are undertaken to measure thermophysical properties of Ni-based superalloys in the high-temperature solid ${ }^{[7,8]}$ and in the liquid phase. ${ }^{[9-11]}$ Because of the large variety of Ni-based superalloys, predictive models for the values of a variety of thermophysical properties have been developed. ${ }^{[12]}$ The models require reliable input data at selected alloy compositions to allow for proper scaling over a larger concentration range.

Measurements of thermophysical properties in the liquid phase at high temperatures with conventional thermoanalytic equipment are often complicated and fraught with error because of the presence of chemical or dissolution reactions between the liquid and the container holding it. The various thermophysical properties are affected to a different extent by such reactions depending on alloy composition, temperature, and container material.

Containerless processing for thermophysical property measurement based on electromagnetic ${ }^{[13,14]}(\mathrm{eml})$ and electrostatic levitation ${ }^{[15-18]}$ (esl) offers an alternative approach. Electromagnetic levitation appears to be more versatile regarding the large variety of metallic and semiconducting alloys to which it was successfully applied as well as its applicability under different gas atmospheres and in vacuum. 
In this contribution, measurements of the surface tension and viscosity of the Ni-based superalloys LEK94 and CMSX-10 with the oscillating drop method in an electromagnetic levitation device on board a parabolic flight airplane are described. While the non-contact measurement of the surface tension can also be performed in ground-based eml and with an appropriate gas atmosphere in the esl, measurements of the viscosity require non-turbulent fluid flow conditions which in em-levitation can only be achieved under microgravity (micro-g). Ni-based superalloys have liquidus temperatures in the range of $T_{\text {liq }}=1680 \pm 50 \mathrm{~K}$ $\left(1407 \pm 50^{\circ} \mathrm{C}\right)$. Regarding chemical reactivity in the liquid phase close to the liquidus temperature, Ni-based superalloys are at an intermediate position still allowing thermophysical property measurement with conventional equipment with reasonable accuracy. Considerations have to be made for elements such as Al and $\mathrm{Hf}$ which are readily oxidized and may, thus, affect the results of thermophysical property measurements in the liquid state. As such, the measurements presented here are intended to provide comparison data to those obtained by other methods.

\section{EXPERIMENTAL ELEMENTS}

\section{A. Experimental Setup and Processing}

The experiments were performed with a radio frequency (rf) electromagnetic levitation device on board a parabolic flight airplane. Each parabola provided about 20 seconds of micro-g. For the Ni-based superalloys, this time is sufficient to heat, melt, heat into the liquid phase, and cool to solidification. Details of the levitation facility and data evaluation have been described elsewhere. ${ }^{[9,19]}$ In short, metallic specimens are positioned in the center of two superimposed radio frequency (rf-) current carrying induction coils, generating a rf-magnetic dipole field for heating and a rf-magnetic quadrupole field for positioning. The whole setup is contained in a high vacuum compatible chamber equipped with feedthroughs for the rf-power lines, observation windows for temperature measurement and optical observation and with a gas circulation system. Before the start of the micro-g phase of a parabola samples are preheated to about $1173 \mathrm{~K}\left(900^{\circ} \mathrm{C}\right)$ in an atmosphere of 4 to 6 mbar argon. Upon reaching the micro-g phase, the sample is heated into the liquid phase to a set temperature. After having reached this temperature, the rf-heater is turned off and the chamber is flooded with $400 \mathrm{mbar}$ highly heat conducting Helium gas. Due to the short micro-g time, conduction cooling in He besides the radiation cooling is required to complete such a temperature-time cycle within the available 20 seconds of micro-g time.

Evaluation of the experimental data requires knowledge of the sample temperature in the liquid phase. The sample temperature in the parabolic flight facility is measured with a single-channel optical pyrometer with an InGaAs detector in the wavelength range of 1.45 to $1.8 \mu \mathrm{m}$, and the temperature range was from $673 \mathrm{~K}$ $\left(400{ }^{\circ} \mathrm{C}\right)$ to $2473 \mathrm{~K}\left(2200{ }^{\circ} \mathrm{C}\right)$. The pyrometer was integrated into the axial camera and has the same viewing direction. It was focussed to a 3-mm-diameter spot on the top of the sample. The emissivity setting of the pyrometer was calibrated at the solidus temperatures of spherical test specimen of the same dimension as the flight specimen. Calibration tests were performed in ground-based laboratory on solid samples in a high vacuum chamber with the same inductive heating setup as in the parabolic flight experiment and with the same optical setup. The solid samples were supported on a 1.0-mm-diameter $\mathrm{Al}_{2} \mathrm{O}_{3}$ rod. The samples were heated and the onset of melting as observed on the temperature-time curve was taken to fix the pyrometer emissivity setting to match the known onset of melting. ${ }^{[20]}$ No further adjustments to the pyrometer emissivity setting in the parabolic flight experiments were made. The reproducibility of the liquidus temperature on the temperature-time profiles of all parabolas was better $5 \mathrm{~K}$ indicating no major sample contamination in the course of processing. Final data evaluation require the correlation between temperature versus time and sample deformation versus time. This correlation was performed by a series of light pulses which could be detected in the temperature and in the video recordings. ${ }^{[21]}$ The liquidus temperature obtained from calorimetry measurements, see Section II-C, was then used for the final adjustment of the sample temperature in the liquid phase.

The sample shape was recorded by two digital cameras: one in the axial direction along the axis of the dipole heating field and one in the perpendicular radial position with frame rates of 150 and $200 \mathrm{~Hz}$, respectively. The process chamber was equipped with a gas flow unit and could be operated under static gas, circulating gas flow, and under vacuum. Argon and helium gas in adjustable ratio and flow rate could be used for convective cooling. The gas flow lines were equipped with gas purification cartridges providing a nominal purity of the process gas atmosphere $<1 \mathrm{ppm}$ $\mathrm{O}_{2}$ and $\mathrm{H}_{2} \mathrm{O}$. The process chamber is connected to a sample chamber holding up to 8 samples on a rotation stage. Samples were contained in a sample holder with a cage structure on top which can be moved into the center of the rf-heating and positioning coils by a transport mechanism.

A typical temperature time profile of processing a LEK94 specimen in one parabola is shown in Figure 1 exhibiting heating in the solid phase, melting, heating in the liquid phase and cooling to solidification. During the cooling phase with the rf-heating generator turned off, two pulses of the rf-heater field with 0.10 seconds duration are applied to excite surface oscillations. Care was taken to apply a minimum pulse amplitude to avoid a large initial sample deformation which could lead to an increased contribution of the non-linear term in the Navier-Stokes equation affecting the evaluation of the viscosity from the measured damping time constant of the surface oscillations. ${ }^{[2,23]}$ The large temperature variations observed during heating in the solid phase originate from sample movement caused by micro-g disturbances. Both samples exhibited an undercooling of 
$\Delta T_{\mathrm{u}}=90 \pm 20 \mathrm{~K}\left(90 \pm 20^{\circ} \mathrm{C}\right)$ in all parabolas, indicating the cleanness of the specimen. In addition to the optical recording, surface oscillations of the liquid specimen could also be evaluated from the recording of the rf-heating generator oscillating circuit current, voltage, and phase shift which generate the rf-magnetic levitation field. The rf-eddy current in the sample, originally induced in the sample by this field, reversely induces an additional voltage in the coil ${ }^{[24]}$ which is modulated with the surface oscillations of the specimen. An electronic device termed sample coupling electronics (SCE) was integrated in the oscillating circuit ${ }^{[25]}$ of the rf-heating generator to extract these signals. The sampling rate was $400 \mathrm{~Hz}$ and the sensitivity better $10^{-3}$.

\section{B. Sample Materials}

The LEK94 material was provided by an industrial partner to the project. The composition is given in a patent by Glatzel et al. ${ }^{[26]}$ The average composition from the patent is listed in Table I. The CMSX-10 alloy was fabricated by alloying the elemental materials according to a composition given by Erickson. ${ }^{[27]}$ The composition of the final alloy measured by EDX and the targeted composition are given in Table I. With the exception of $\mathrm{Hf}$, all second digits past the comma are rounded. The measured Hf content of CMSX-10 listed in Table I is within statistical error compatible with zero. EDX analysis of multicomponent alloys without a dedicated standard cannot be expected to be of high accuracy. As such, composition accuracy is guaranteed by proper weighing of the elemental components and accounting for possible weight loss during alloying.

For the fabrication of CMSX-10 lower melting point eutectic or near eutectic pre-alloys between the low and high melting point elements were first made to assure complete dissolution of the refractory elements. Composition accuracy was assured by weight control of the alloy components. Proper weight cut pieces of the pre-alloys were then further alloyed with $\mathrm{Al}$ and $\mathrm{Ni}$ to

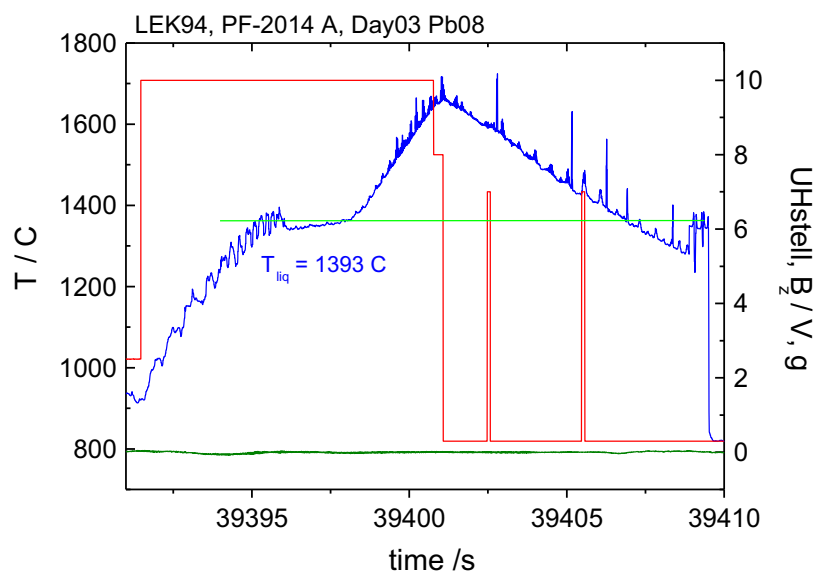

Fig. 1-Temperature-time profile of processing a LEK94 specimen during one parabola. Temperature is shown on the left hand ordinate, indicated by an arrow. The heater control voltage and the microgravity level are shown on the right-hand ordinate. The dashed horizontal line indicates the liquidus temperature. obtain the final CMSX-10 composition. Ingots were cast into 5-mm-diameter rods in a water-cooled copper mold. Slices were cut from different locations on the rod for SEM and EDX analysis to verify the homogeneity of the cast material and the complete dissolution of the refractory elements. As the alloy was intended for processing in the liquid phase, no effort for solution heat treatment was made.

The spherical samples of $6.5 \mathrm{~mm}$ diameter for processing in the parabolic flight were cast by suction casting of proper weight cut alloy pieces in a watercooled copper mold in an arc melter. After casting runners and feeders were cut off with a diamond cutting blade. The samples were grinded to a mirror finish under flowing water, cleaned in an ultrasonic bath with isopropanol and diethyl ether, and degassed for about 2 hours at $T=393 \mathrm{~K}\left(120^{\circ} \mathrm{C}\right)$ in high vacuum. The average sample diameter was $6.5 \mathrm{~mm}$. The samples were weighed on a precision scale to an accuracy better 0.1 pct. Before the parabolic flight experiments, the sample weights were 1.196 and $2.003 \mathrm{~g}$ for LEK94 and CMSX-10, respectively. After processing, a weight loss of $5 \mathrm{mg}$ was observed for LEK94, while within an accuracy of $\pm 1 \mathrm{mg}$ no weight change was observed for CMSX-10. Samples were stored and packed in a glove box under high-purity Ar.

Oxygen analysis with the LECO hot gas extraction method was performed in a certified laboratory on samples produced in the same series as the samples to be tested in the parabolic flight. For both alloys, an oxygen concentration of $<10 \mathrm{wt}$ ppm was obtained. Similar analysis was performed on the parabolic flight processed specimen giving an oxygen concentration $<10 \mathrm{ppm}$ for both specimen.

\section{Thermal Analysis}

The calorimetric measurements were performed with a high-temperature dual-pan calorimeter. The instrument-specific thermal relaxation time was accounted for by application of different heating rates and extrapolation to heating rate zero. The measurements were performed in $\mathrm{Al}_{2} \mathrm{O}_{3}$ cups coated on the inside with $\mathrm{Y}_{2} \mathrm{O}_{3}$ and inserted into Pt cups. Results are given in Table II. The liquidus temperature of CMSX-10 given by Liv et al. ${ }^{[26]}$ differs from the one given here by $-7 \mathrm{~K}$ $\left(-280.15^{\circ} \mathrm{C}\right)$ and a recently published value by Amore et al. ${ }^{[10]}$ by $+19 \mathrm{~K}\left(-254.15^{\circ} \mathrm{C}\right)$. These discrepancies highlight the difficulty of obtaining accurate liquidus temperatures of high melting point alloys with an absolute accuracy of $<5 \mathrm{~K}\left(-268.15^{\circ} \mathrm{C}\right)$.

The evaluation of the viscosity from the damping time constant of the surface oscillation requires knowledge of the sample radius and mass. The mass is known from precision weighting of the experiment samples. The radius of an ideal spherical sample at room temperature $(R T)$ was determined from the mass and the density. The density at RT was evaluated by the pycnometer method. Results are listed in Table II. For CMSX-10, the measured density at RT agrees very well with a value of $\rho(\mathrm{RT})=9.05 \mathrm{~g} \mathrm{~cm}^{-3}$ given by Quested et al. ${ }^{[28]}$ Scaling of the sample radius from $R T$ to the solidus 
Table I. Composition of LEK94 and CMSX-10 in Weight Percent

\begin{tabular}{lccccccccrrr}
\hline Element & Cr & Co & Mo & W & Ta & Re & Al & Ti & Hf & Nb & Ni \\
\hline LEK94 & 6.8 & 7.4 & 1.4 & 1.4 & 0.9 & 0.9 & 15.2 & 1.2 & 0.08 & - \\
CMSX-10 & 2.1 & 3.1 & 0.5 & 5.2 & 8.3 & 4.7 & 6.3 & 0.2 & 0.15 & 0.10 & 69.7 \\
& 2.0 & 3.0 & 0.4 & 8.0 & 8.0 & 6.0 & 5.7 & 0.2 & 0.03 & 0.10 & 66.6 \\
\hline
\end{tabular}

The composition of LEK94 was taken from Ref. [24] as average values between minimum and maximum concentrations. The composition of CMSX-10 given in the first row was measured by EDX. The composition in the second row is the targeted composition as given in Ref. [25].

Table II. $\quad T_{\text {sol }}, T_{\text {liq }}$ Solidus and Liquidus Temperatures, Numbers in Parentheses: Values in ${ }^{\circ} \mathrm{C}$

\begin{tabular}{|c|c|c|c|c|c|c|}
\hline Alloy & $T_{\text {sol }}\left[\mathrm{K}\left({ }^{\circ} \mathrm{C}\right)\right]$ & $T_{\text {liq }}\left[\mathrm{K}\left({ }^{\circ} \mathrm{C}\right)\right]$ & $\Delta L / L_{\mathrm{o}} \times 10^{2}$ & $\rho_{\mathrm{RT}}\left(\mathrm{g} \mathrm{cm}^{-3}\right)$ & $\rho\left(T_{\mathrm{sol}}\right)\left(\mathrm{g} \mathrm{cm}^{-3}\right)$ & $\rho\left(T_{\text {liq }}\right)\left(\mathrm{g} \mathrm{cm}^{-3}\right)$ \\
\hline LEK94 & $1607 \pm 4(1334 \pm 4)$ & $1666 \pm 4(1393 \pm 4)$ & +2.55 & 8.33 & 7.72 & 7.49 \\
\hline CMSX-10 & $1651 \pm 4(1378 \pm 4)$ & $1683 \pm 4(1410 \pm 4)$ & +2.69 & 9.02 & 8.33 & 8.08 \\
\hline
\end{tabular}

$\rho_{\mathrm{RT}}, \rho\left(T_{\mathrm{sol}}\right), \rho\left(T_{\mathrm{sol}}\right)$ densities at room temperature, at $T_{\text {sol }}$ and at $T_{\text {liq }}$, respectively, the value at $T_{\text {liq }}$ for CMSX-10 was taken from Ref. [27]; $\Delta L / L_{\mathrm{o}}$ : relative linear length change between RT and $T_{\text {sol. }}$.

temperature was performed by dilatometer measurements. Results of the relative length change, $\Delta L / L_{\mathrm{O}}$, between RT and $T_{\text {sol }}$ are given in Table II. For CMSX-10, the density in the liquid phase was measured with the sessile drop by Mills et al. ${ }^{[29]}$ as $\rho\left(T_{\text {liq }}\right)=8.081$ $\mathrm{g} \mathrm{cm}^{-3}$. With our value at $T_{\text {sol }}$ of $\rho\left(T_{\text {sol }}\right)=8.33 \mathrm{~g} \mathrm{~cm}^{-3}$, a volume change at melting of $+2.96 \mathrm{pct}$ is derived. The same value is assumed for LEK 94 resulting in a density $\rho\left(T_{\text {liq }}\right)=7.49 \mathrm{~g} \mathrm{~cm}^{-3}$. From these values, the change of the sample radii between $\mathrm{RT}$ and $T_{\text {liq }}$ is obtained as +3.4 pet for CMSX-10 and LEK94 with an estimated error of max. \pm 10 pct. This error translates to an error of $<1$ pet in the evaluation of the viscosity and will be neglected.

\section{DATA EVALUATION}

The oscillations of a liquid sphere under $1-\mathrm{g}$ and micro-g conditions have been described in detail by various authors. ${ }^{[30-33]}$ In equilibrium or following pulse excitation, the sample oscillates in the $Y_{2 \mathrm{~m}}$ modes after higher order modes have decayed. $Y_{2 \mathrm{~m}}$ represents the spherical harmonics of order 2 with $m=0, \pm 1, \pm 2$. Under micro-g conditions, the frequencies of the $m=0$, $\pm 1, \pm 2$ oscillations are degenerated resulting in a single oscillation frequency, $v_{\mathrm{R}}$, which is related to the surface tension by Rayleigh's ${ }^{[34]}$ formula according to

$$
\sigma=\frac{3}{8} \pi v_{R}^{2} M
$$

with $M$ the mass of the sample. Under $1-g$ conditions and for a non-spherical specimen, the degeneracy of the different $m$ modes is removed resulting in a five peaked oscillation spectrum. This is observed in ground-based electromagnetic levitation which requires a levitation field with a strong gradient in the direction of the g-vector causing a deformation of the liquid sample. In addition, the magnetic pressure on the sample surface causes a shift of the oscillation frequencies.
This shift was calculated by Cummings and Blackburn. ${ }^{[35]}$ In this correction, the magnetic pressure on the specimen is expressed in terms of the center of mass oscillation frequencies. The validity of the Cummings and Blackburn correction formula was verified by a comparison of surface tension values obtained by the oscillating drop method in an electromagnetic levitation device in ground-based laboratory and under micro-g conditions. ${ }^{[36-38]}$ Under micro-g conditions, the remaining force on the sample results from the quadrupole positioning field which is much reduced in comparison to the $1 \mathrm{-g}$ case but is still needed to keep the sample in the coil center against external residual disturbances. The center of mass oscillation frequencies are easily measured and can be applied with the Cummings and Blackburn formula to correct the measured surface oscillation frequency for the effect of the residual magnetic field pressure according to

$$
v_{R}^{2}=v_{M}^{2}-1.9 v_{\mathrm{tr}}^{2}-0.3 v_{\mathrm{tr}}^{-2}\left(\frac{g}{R}\right)^{2}
$$

with $v_{M}$ the measured surface oscillation frequency, $v_{R}$ the undisturbed Rayleigh frequency, $v_{\mathrm{tr}}$ the average of the center of mass oscillation frequencies in perpendicular directions, $g$ the gravitational constant, and $R$ the sample radius. Average center of mass translation frequencies were in the range of $v_{\mathrm{tr}}=2.6 \pm 0.4 \mathrm{~Hz}$ resulting in a correction of -3.4 pct of the measured $v_{M}^{2}$ to obtain the Rayleigh frequency from which the surface tension was calculated.

The effects of sample rotation and precession on the oscillation spectra observed under micro-g conditions were investigated by Higuchi et al. ${ }^{[39,40]}$ and by Egry et al. ${ }^{[41]}$ showing that under micro-g conditions, the single frequency oscillation spectrum is symmetrically split into two or more peaks. This is a purely kinematic effect. The symmetric splitting allows in principle an unambiguous identification of the center oscillation frequency. ${ }^{[42]}$ The precision of the determination of the oscillation frequency is primarily determined by the 
sampling time per data point and by the sampling rate. Additional effects are the possibility of mode jumps and non-quiescent positioning conditions from micro-g variations. The sampling time per data point is limited by the cooling rate. An increased sampling time results in an increase of the temperature range over which that data point is averaged.

Under the assumptions of laminar flow and a small surface deformation, the viscosity, $\eta$, is evaluated from the damping time constant of the surface oscillations, $\tau$, as ${ }^{[43]}$

$$
\eta=\frac{3}{20 \pi} \frac{M}{R} \tau^{-1}
$$

with $R$ the radius of the sample. Care was taken to reduce the amplitude of the surface oscillation excitation amplitude to a minimum value ${ }^{[4]}$ which still allowed to analyze the surface oscillations. The precision of the determination of the damping time constant is estimated as \pm 20 pct.

The evaluation of surface oscillations from the digital image recordings has been described in detail elsewhere. ${ }^{[37]}$ The sample perimeter was obtained from a standard edge detection algorithm. Different measures of the sample shape deformation are applied, such as the length of two perpendicular radii, their sum and difference, the total projected area, the difference of the projected area with respect to that of an ideal sphere with the same nominal diameter. The default orientation of the analysis coordinate system axes is with the y-axis coinciding to the dipole field axis which corresponds to the symmetry of the $Y_{20}$ oscillation mode as observed with the radial camera. The orientation of the analysis coordinate system could be rotated by a fixed angle and with a constant angular velocity to alleviate the effects of sample rotation and precession on the evaluation of the damping time constant and oscillation spectra.

As an example, Figure 2(a) shows the variation of the sum of two perpendicular radii as a function of time together with the rf-heater control voltage showing two pulses for the excitation of surface oscillations. The variation of the radius sum was extracted from the measured sample radii as a function of time by application of a high pass Fourier transform filter. Figure 2(b) shows the Fourier Transform (FFT) of the time slice indicated in Figure 2(a) from which the surface oscillation frequency was determined. Time intervals used for the FFT ranged from 0.4 to 0.8 seconds. With an average cooling rate of $50 \mathrm{~K} \mathrm{~s}^{-1}\left(-223.15^{\circ} \mathrm{C} \mathrm{s}^{-1}\right)$, each surface tension data point represents an average over a temperature range of $\pm 20 \mathrm{~K}\left(-253.15^{\circ} \mathrm{C}\right)$ to $\pm 45 \mathrm{~K}\left(-228.15^{\circ} \mathrm{C}\right)$. The accuracy of the surface oscillation frequency as obtained from the Fourier transform is $<4$ pct. Ideally, the variation of the sample radius as a function of time should exhibit a purely exponential time dependence.

As an example of the inductive method for the analysis of sample surface oscillation, the variation of the rf-heater generator oscillating circuit current amplitude, $I_{0}(t)$, following pulse excitation is shown Figure 3(a). The variation of $I_{0}(t)$ originating from the change of the sample electrical resistivity as a function of temperature along the cooling curve occurs on a

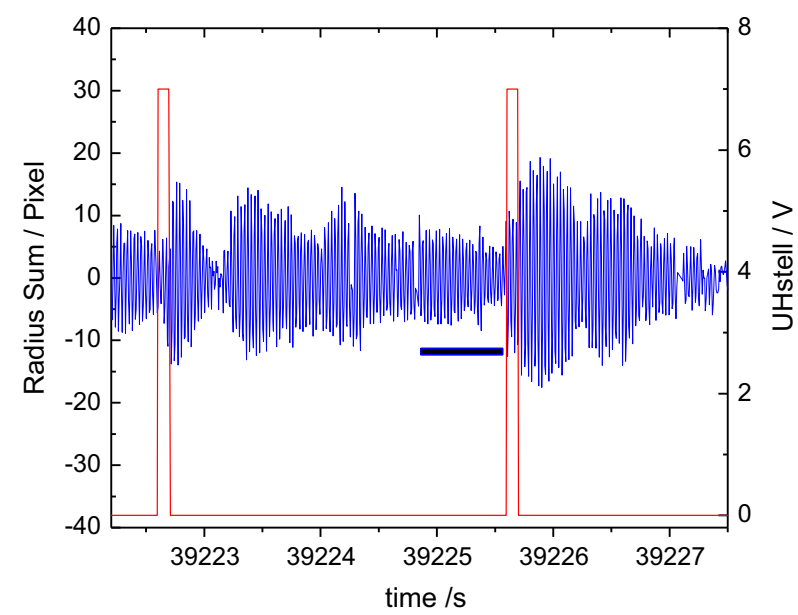

(a)

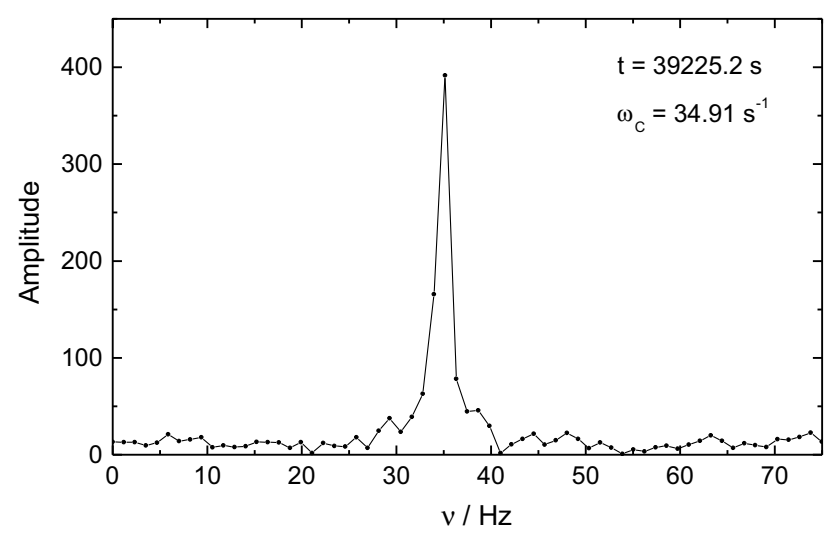

(b)

Fig. 2-(a) LEK94. Axial camera, $150 \mathrm{~Hz}$ recording, variation of the sum of two perpendicular radii shown on the right-hand ordinate; rf-heater control voltage shown on the left-hand ordinate. Horizontal bar indicates times slice used for the Fourier transformation shown in (b). (b) Fourier transform of the radius sum variation in the time slice indicated in (a).

much larger time scale than the surface oscillations and has been filtered out by a high pass filter similar to the analysis of the optical data. The surface oscillation spectrum obtained from a FFT of the time domain signal following the second excitation pulse is shown in Figure 3(b). The $400 \mathrm{~Hz}$ data acquisition results in a sharply peaked frequency spectrum. The full line represents a Lorentzian fit allowing the determination of the center oscillation frequency with an accuracy $< \pm 0.5 \mathrm{~Hz}$. The inductive method is not completely immune to the effects of rotation and center of gravity oscillation on the observed oscillation spectra.

The time domain signals following the excitation pulses can be well fitted with an exponential envelope from which the damping time constants are evaluated. Instead of an exponential envelope, the decay time constant can equally well be evaluated from a linear fit to a logarithmic plot of the squared current variation.

In the absence of sample rotation, the width of a single frequency peak is determined by the damping time 


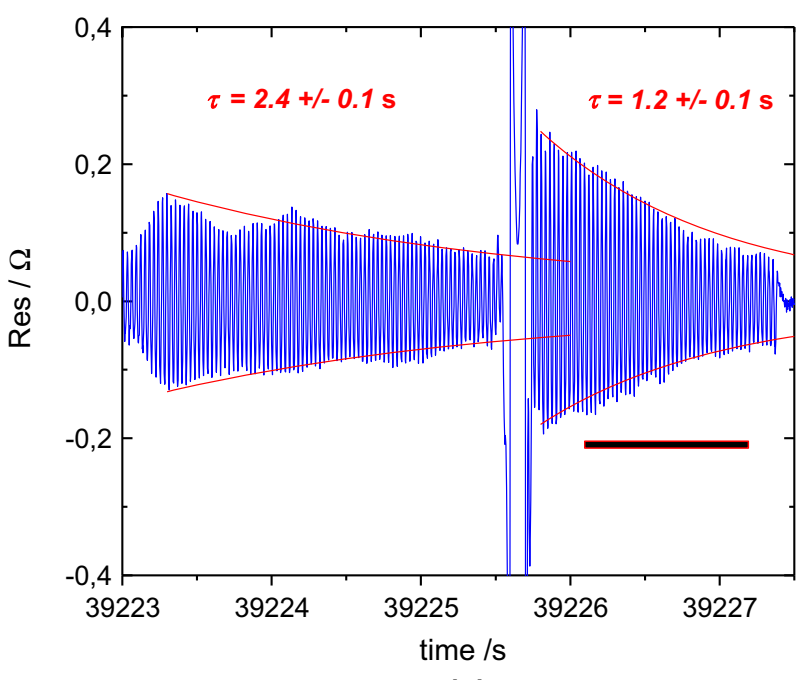

(a)

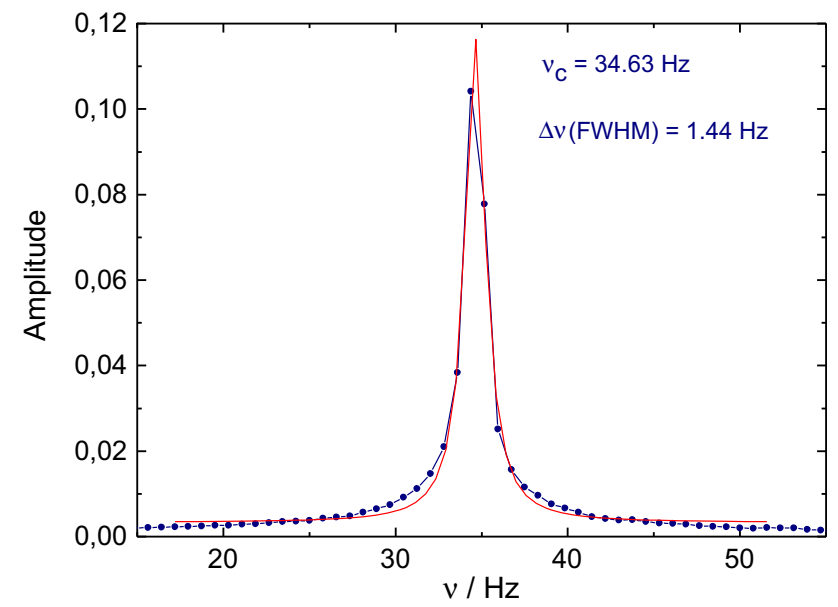

(b)

Fig. 3-(a) LEK94. Variation of the rf-heater oscillating current obtained from the SCE. The horizontal bar indicates the time slice used for the Fourier transform as shown in (b). (b) LEK94. Fourier transform of the time signal following the second excitation pulse as shown in (a). Dotted line: Fourier transform; full line: Lorentzian fit. constant and by the finite sampling interval. For the signal as shown in Figure $3(\mathrm{~b})$, the width at half maximum obtained from the Lorentzian fit is $\Delta v=$ $1.44 \mathrm{~Hz}$. The finite sampling time of $\Delta t_{\mathrm{s}}=1.6$ seconds contributes $\Delta v_{\mathrm{s}}=0.63 \mathrm{~Hz}$ to the observed spectral width resulting in a damping time contribution of $\Delta v_{\mathrm{d}}=$ $0.81 \mathrm{~Hz}$ which corresponds to a damping time constant of $\Delta t_{\mathrm{d}}=1.23$ seconds. This value agrees very well with the damping time constant evaluated from the exponential envelope fit. This is, however, not the regular case. In many instances, the time domain signal exhibits a modulation resulting in split and broadened oscillation spectra.

\section{RESULTS}

\section{A. Surface Tension}

The surface tension of LEK94 as a function of temperature obtained from a single parabola is shown in Figure 4 combining data evaluated from the optical recording and from the inductive coupling. The two data sets exhibit very good agreement; linear fits to both data sets agree to better than 0.5 pct over the whole data range. The larger scatter of the optical data originated from sample movement in the rf-induction coil caused by disturbances in the micro-g quality. In Figure 5, similar data sets are shown for the CMSX-10 alloy. The surface tension as a function of temperature can be well represented by a linear dependence with a negative temperature coefficient. In Table III, the average values of the surface tension at the liquidus temperature and of the temperature coefficient from all parabolas analyzed are listed. For comparison, the values of the Ni-based superalloy CMSX-4 obtained in a previous parabolic flight $^{[19]}$ are included.

\section{B. Viscosity}

In Figures 6(a, b) and 7(a, b), the viscosities of LEK94 and CMSX-10 are shown as a function of

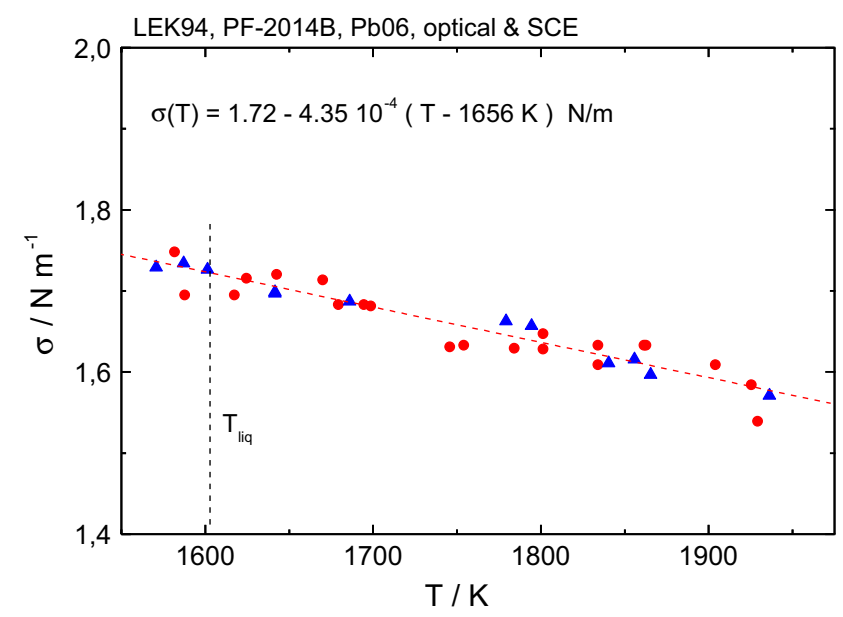

Fig. 4-Surface tension of LEK94 as a function of temperature. Shown are values obtained from a single parabola. ( $)$ : values evaluated from optical recording; $(\boldsymbol{\Delta})$ : values evaluated from the sample coupling electronics SCE. The full line is a linear fit to the SCE data. 


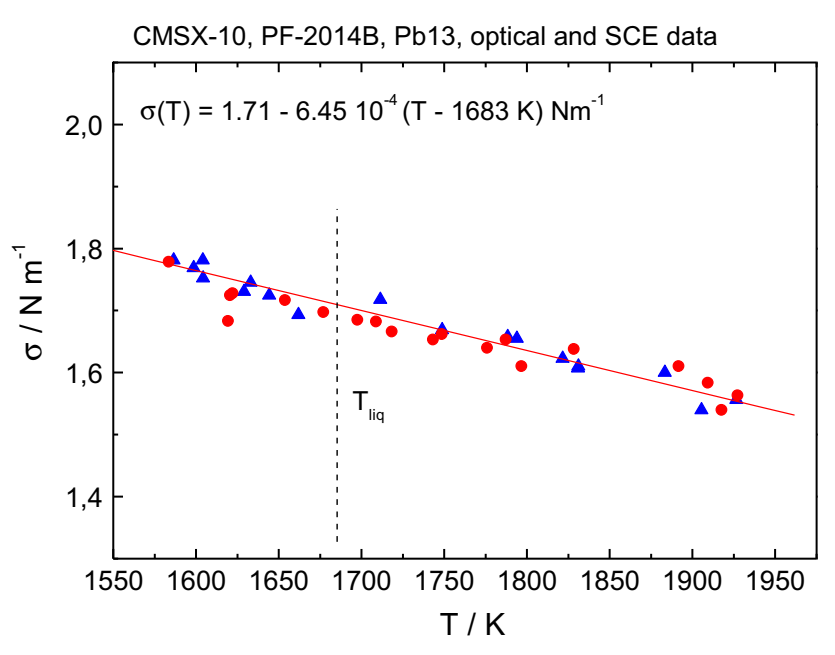

Fig. 5-Surface tension of CMSX-10 as a function of temperature, values from a single parabola. ( $)$ : evaluated from optical recording; $(\boldsymbol{\Delta})$ : values evaluated from the sample coupling electronics. The full line: linear fit to the SCE data, dashed line: liquidus temperature.

Table III. Surface Tension, $\sigma_{0}$, at $T_{\text {liq }}$ and Temperature Coefficient, $\mathrm{d} \sigma / \mathrm{d} T$, of the Alloys LEK94, CMSX-10, and CMSX-4

\begin{tabular}{lcc}
\hline Alloy & $\sigma_{\mathrm{o}}\left(\mathrm{Nm}^{-1}\right)$ & $\mathrm{d} \sigma / \mathrm{d} T\left[\mathrm{Nm}^{-1} \mathrm{~K}^{-1}\left(\mathrm{Nm}^{-1}{ }^{\circ} \mathrm{C}^{-1}\right)\right]$ \\
\hline LEK94 & $1.73 \pm 0.02$ & $-4.51 \times 10^{-4}$ \\
CMSX-10 & $1.71 \pm 0.02$ & $-5.80 \times 10^{-4}$ \\
CMSX-4 & $1.79 \pm 0.02$ & $-9.09 \times 10^{-4}$ \\
\hline
\end{tabular}

The values for LEK94 and CMSX-10 are averages from four parabolas. CMSX-4 values are from Ref. [9].

temperature and in the Arrhenius depiction, respectively. The scatter of the data originates from sample movement caused by unsteady micro-g conditions which affect the evaluation of the damping time constant more than that of the surface tension because of the smaller time scale involved in the latter. The viscosity as a function of temperature can be reasonably well fitted by an exponential decay. For LEK94, the Arrhenius plot can be well fitted by a linear function. In the Arrhenius plot for CMSX-10, a deviation from a linear dependence is observed for $T<T_{\text {liq }}$ in the undercooled liquid phase. The higher viscosities in this temperature range and the large scatter result from the onset of crystallization which increases the viscosity which no longer refers to a Newtonian fluid. Thus, for the linear fit as shown in Figure 7(b), only viscosity values for temperatures $T>$ $T_{\text {liq }}-20 \mathrm{~K}\left(-293.15^{\circ} \mathrm{C}\right)$ were considered. In Table IV, the viscosities at the liquidus temperature and the Arrhenius constants obtained in this work and the viscosity of CMSX-4 from Reference 19 are listed.

\section{DISCUSSION}

\section{A. Surface Tension}

At the liquidus temperature, the surface tension of LEK94 and CMSX-10 agrees within error limits. For both alloys over a temperature range of $400 \mathrm{~K}$ $\left(126.85^{\circ} \mathrm{C}\right)$, the surface tension exhibits a linear temperature dependence with a negative temperature coefficient in the range of -4 to $-6 \times 10^{-4} \mathrm{Nm}^{-1} \mathrm{~K}^{-1}$. This values fall well within the range of temperature coefficients reported for the Ni-based superalloys. The surface tension of CMSX-10 was measured by Li et al. ${ }^{[45]}$ by the sessile drop method. At the liquidus temperature, a value of $\sigma\left(T_{\text {liq }}\right)=1.79 \mathrm{Nm}^{-1}$ was obtained. In the same work, the surface tension of CMSX-4 at $T_{\text {liq }}$ was obtained as $\sigma\left(T_{\text {liq }}\right)=1.81 \mathrm{Nm}^{-1}$ in good agreement with our previously reported value of $\sigma\left(T_{\mathrm{liq}}\right)=1.79 \mathrm{~N}$ $\mathrm{m}^{-1}$. For CMSX-4, Ricci et al. $^{[46]}$ reported a value $\sigma\left(T_{\mathrm{liq}}\right)=1.77 \mathrm{~N} \mathrm{~m}^{-1}$ and a temperature coefficient of $-5.6 \times 10^{-4} \mathrm{~N} \mathrm{~m}^{-1} \mathrm{~K}^{-1}$ measured by the pinned drop method. For Rene N5 and Rene90, values of $\sigma\left(T_{\text {liq }}\right)=$ $1.75 \mathrm{~N} \mathrm{~m}^{-1}$ and $\sigma\left(T_{\text {liq }}\right)=1.85 \mathrm{~N} \mathrm{~m}^{-1}$ were reported by Giuranno et al. ${ }^{[47]}$ As such, the values of $\sigma\left(T_{\text {liq }}\right)$ obtained for CMSX-10 and LEK-94 in this work are in the lower range of reported surface tension values for the Ni-based superalloys.

As compared to CMSX-4, CMSX-10 has lower $\mathrm{Cr}$ and $\mathrm{Co}$ and about 2.5 at. pct higher $\mathrm{Al}$ content. In a model developed by Novakovic and Ricci, ${ }^{[48]} \mathrm{Ni}$-Al was identified as the dominant subsystem which determines the concentration dependence of the surface tension in Ni-based superalloys. As the Al contents of CMSX-10 and LEK94 agree within 1.2 at. pct, the surface tension of both alloys should also be very similar which is indeed observed. This implies that the difference of the $\mathrm{Cr}$ and Co concentration between LEK94 and CMSX-10 has little effect on the surface tension. This can be understood by the fact that the difference is balanced with $\mathrm{Ni}$ which has a rather similar surface tension of $\sigma\left(T_{\mathrm{m}}\right)=1.79 \pm 0.02 \mathrm{~N} \mathrm{~m}^{-1}$, as given by Egry et al. ${ }^{[49,50]}$ as $\mathrm{Cr}$ and Co with $\sigma\left(T_{\mathrm{m}}\right)=1.72 \pm 0.02$ $\mathrm{Nm}^{-1}$ and $\sigma\left(T_{\mathrm{m}}\right)=1.93 \pm 0.02 \mathrm{Nm}^{-1}$, respectively. ${ }^{[51,52]}$ And, by the dominance of Al surface segregation in this alloy system. Over all, it appears that the effect of $\mathrm{Al}$ is to lower the surface tension by about 6 to 8 pct as compared to an ideal mixture of the transition and refractory metals. This is much less than what would be expected in an ideal solution model from the addition of $14 \pm 3$ at. pct Al to a given mixture of transition and refractory elements. Moreover, simple surface segregation of pure $\mathrm{Al}$ as to be expected from its lower surface tension would further lower the surface tension below the ideal mixing values. This very qualitative considerations give support to the complex surface composition models developed for the Ni-based superalloys Novakovic and Ricci. ${ }^{[48,53]}$

\section{B. Viscosity}

Only few data of the viscosity of Ni-based superalloys are available in the open literature. Published viscosity values for Ni-based superalloys at their liquidus temperatures fall in the range between 5.0 and $8.5 \mathrm{mPa}$.s as exemplified by e.g., for IN718 $8^{[54]}$ and CMSX-4, ${ }^{[55]}$ respectively. Other values are e.g., 7.4, 7.9, and 8.1 mPa.s for TMS75, CMSX-4, and IN-713LC, respectively, obtained by Sato ${ }^{[1]}$ with the oscillating cup 


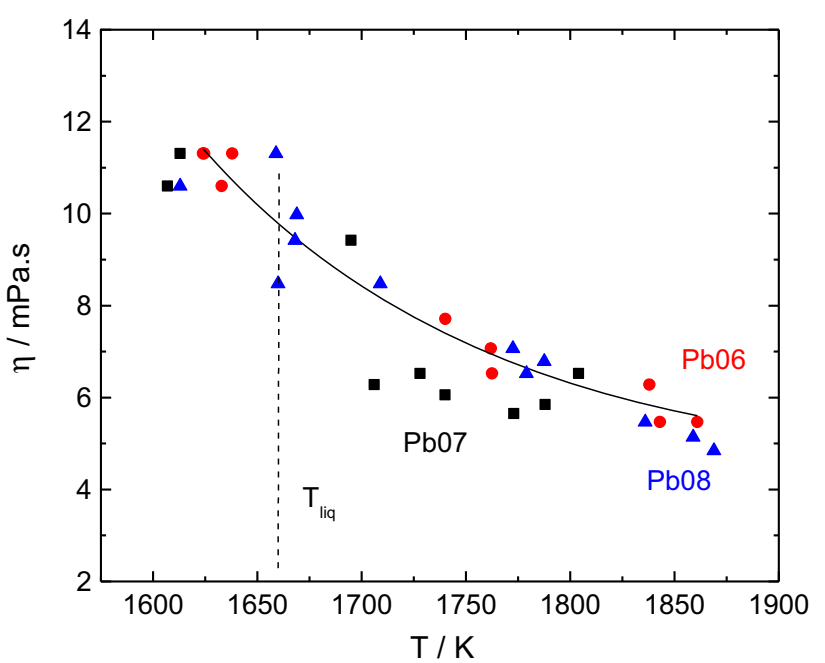

(a)

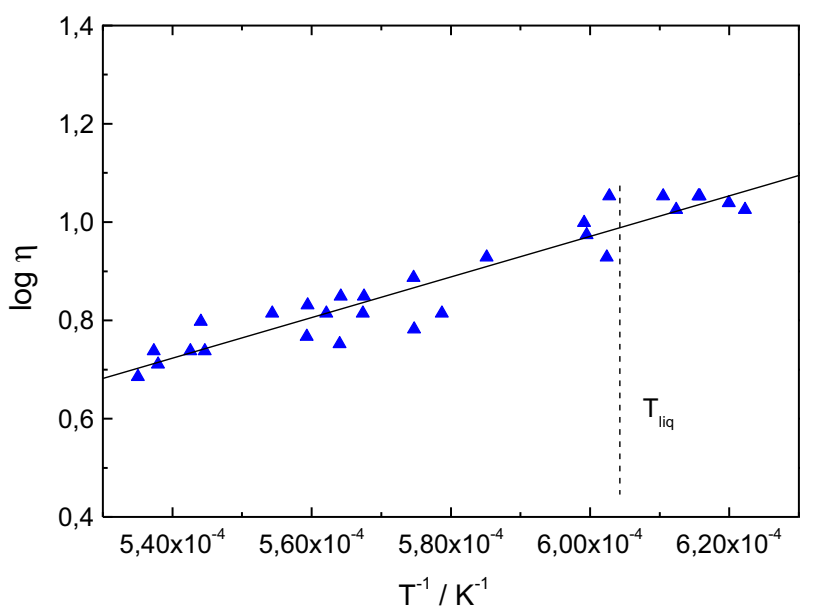

(b)

Fig. 6 - (a) LEK94. Viscosity as a function of temperature. Results from three parabolas. (b) LEK94. Arrhenius plot of the viscosity. Results from all parabolas.

method. As such, the viscosity for CMSX-10 obtained in this work falls well within the range of published data for Ni-based superalloys while the value for LEK94 is at the high end.

A series of viscosity measurements of the binary Ni-M constituents of the Ni-based superalloys with $\mathrm{M}=\mathrm{Al}$, $\mathrm{Co}, \mathrm{Cr}, \mathrm{Ta}, \mathrm{W}$ as a function of composition and temperature were performed by Sato ${ }^{[57]}$ showing that Ta and $\mathrm{W}$ have the most pronounced effect on the viscosity increase with respect to the value of pure Ni of $\eta\left(T_{\mathrm{m}}\right)=$ $4.80 \pm 0.10$ mPa.s. ${ }^{[56,57]}$ Based on these results and considering its higher Re content, a higher viscosity of CMSX-10 as compared to that of LEK94 is expected. The same arguments hold in comparison with CMSX-4. Scaling of the viscosity of LEK94 to the liquidus temperature of CMSX-10 results in a value of $\eta=8.2$ $\mathrm{mPa} . \mathrm{s}$ which is about 6.5 pct higher than the value for CMSX-10. While this agreement is reasonable, there is no satisfactory explanation for the high viscosity value of LEK94 obtained in this work.

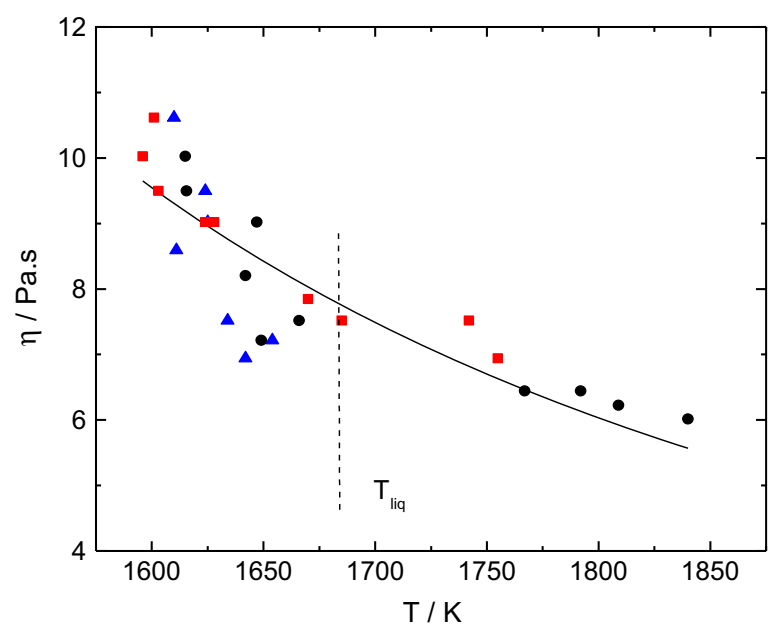

(a)

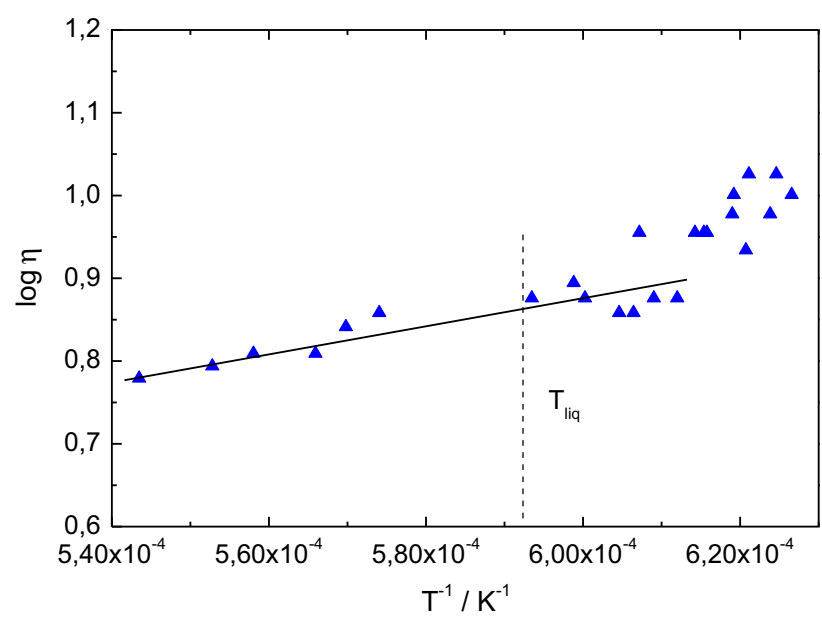

(b)

Fig. 7-(a) CMSX-10. Viscosity as a function of temperature, results from four parabolas. (b) CMSX-10. Arrhenius plot of the viscosity, results from four parabolas. The vertical line indicates the liquidus temperature.

It is interesting to compare the surface tension and the viscosity of the Ni-based superalloys with that of pure $\mathrm{Ni}$. While the surface tension of the $\mathrm{Ni}$-based superalloys is lower than that of pure $N i$, the viscosities are close to a factor of two larger. The reduction of the surface tension of the alloys relative to that of pure $\mathrm{Ni}$ is seen to result from the presence of Al although the reduction is much less than expected from an ideal mixing. In the bulk phase, the viscosity is dominated by the presence of the heavy alloying elements, while the effect of $\mathrm{Al}$ on the viscosity appears to be minimal ${ }^{[58]}$ in comparison to what would be expected from an ideal mixture giving further evidence that in the liquid phase the composition of the free surface of the Ni-based superalloys is different from that of the bulk.

\section{SUMMARY AND PERSPECTIVES}

The surface tension and the viscosity of two Ni-based superalloys, LEK94 and CMSX-10, were measured by 
Table IV. Viscosity of LEK94 and CMSX-10 at the Liquidus Temperature, $\eta\left(T_{\text {liq }}\right) ; \eta_{\mathrm{o}}$ and $\Delta E_{\mathrm{a}}$ Arrhenius Parameters

\begin{tabular}{lcccr}
\hline Alloy & $\eta\left(T_{\text {liq }}\right)(\mathrm{mPa})$ & $\eta_{\mathrm{o}}(\mathrm{mPa} . \mathrm{s})$ & $\Delta E_{\mathrm{a}}\left(\mathrm{eV}\right.$ atom $\left.{ }^{-1}\right)$ & $T_{\text {liq }}\left[\mathrm{K}\left({ }^{\circ} \mathrm{C}\right)\right]$ \\
\hline LEK94 & $9.7 \pm 1.4$ & 0.63 & 0.36 & $1666(1393)$ \\
CMSX-10 & $7.7 \pm 1.2$ & 0.23 & 0.16 & $1683(1410)$ \\
CMSX-4 & $9.6 \pm 1.2$ & 0.31 & 0.42 & $1654(1381)$ \\
\hline \multicolumn{2}{c}{ CMSX-4 values from Ref. [9]. } & & & \\
\hline
\end{tabular}

the oscillating drop method in an electromagnetic levitation device under microgravity conditions in a parabolic flight. Five parabolas were performed with each alloy from which four per alloy provided useable results. The values of the surface tension at the liquidus temperature fall in the lower range of published data for Ni-based superalloys. The viscosity of CMSX-10 at the liquidus temperature is well within the range of published data for the Ni-based superalloys while the viscosity of LEK94 is at the higher end. In the course of the experimental work, thermophysical properties such as solidus and liquidus temperatures, density at room temperature, and thermal expansion up to the solidus temperature were measured. Technically, the raw data from which the surface tension and viscosity were evaluated were of good quality. An improvement of the accuracy and precision is expected from long duration microgravity experiments on the International Space Station, ISS, and extended AC calorimetry and precision density measurements in the liquid phase.

\section{ACKNOWLEDGMENTS}

The parabolic flight was supported by German Space Agency, DLR, and by the European Space Agency, ESA. Support for the project Thermolab by the German Space Agency under Contract 50WM1170 and by the ESA Microgravity Support Programme under Contract $4200014306 / \mathrm{NL} / \mathrm{SH}$ is gratefully acknowledged. Support by MTU Aeroengines with valuable material is gratefully acknowledged. The authors are grateful for the support by the team of the Institut für Materialphysik im Weltraum at DLR Cologne for conducting the parabolic flight experiments with the electromagnetic levitation device in particular to Dr. S. Schneider, Dr. M. Engelhardt, and Dr. D. Heuskin with their teams. Valuable discussions with Dr. P. N. Quested from the National Physical Laboratory, Teddington UK are gratefully acknowledged.

\section{OPEN ACCESS}

This article is distributed under the terms of the Creative Commons Attribution 4.0 International License (http://creativecommons.org/licenses/by/4.0/), which permits unrestricted use, distribution, and reproduction in any medium, provided you give appropriate credit to the original author(s) and the source, provide a link to the Creative Commons license, and indicate if changes were made.

\section{REFERENCES}

1. T.M. Pollock and S. Tim: J. Propuls. Power, 2006, vol. 22, pp. $361-74$.

2. P. Caron: in Superalloys, T.M. Pollock, R.D. Kissenger, R.R. Bowman, K.A. Green, M. McLean, S. Olsen and J.J. Schirra, TMS (The Minerals, Metals \& Materials Society), Warrendale PA, 2000, pp. 737-46.

3. H. Zhang, Q. Xu, and B. Liu: Materials, 2014, vol. 7, pp. 1625-39.

4. W. Wang, P.D. Lee, and B. Liu: Acta Mater., 2003, vol. 51, pp. 2971-87.

5. A. Ludwig: Int. J. Thermophys., 2002, vol. 23, pp. 1131-46.

6. J. Guo, C. Beckermann, K. Carlson, D. Hirvo, K. Bell, T. Moreland, J. Gu, J. Clews, S. Scott, G. Couturier, and D. Backman: IOP Conf. Ser. Mater. Sci. Eng., 2015, vol. 84, p. 012003.

7. P.N. Quested, R.F. Brooks, L. Chapman, R. Morell, Y. Youssef, and K.C. Mills: Mat. Sci. and Technol., 2009, vol. 25, pp. 154-62.

8. R. E. Aune, L.Battezzati, R. Brooks, I. Egry, H.-J. Fecht, J.-P. Garandet, M. Hayashi, K. C. Mills, A. Passerone, P. N. Quested, E. Ricci, F. Schmitt-Hohagen, S. Seetharaman, B. Vinet and R. K. Wunderlich, Superalloys 718, 625706 And Various Derivatives, E. A. Loria, TMS (The Minerals, Metals \& Materials Society), Warrendale, PA 2005, pp. 467-76.

9. K. Higuchi, H.-J. Fecht, and R.K. Wunderlich: Adv. Eng. Mater., 2007, vol. 9, pp. 349-54.

10. S. Amore, F. Valenza, D. Giuranno, R. Novakovic, G. Dalla Fontana, L. Battezzati, and E. Ricci: J. Mater. Sci., 2015, vol. 51, pp. $1680-91$.

11. Y. Sato: Jap. J. Appl. Phys., 2011, 50, 11RD01-1-7.

12. K.C. Mills, Y.M. Youssef, and Z. Li: ISIJ Int., 2006, vol. 46, pp. $50-57$.

13. I. Egry, A. Diefenbach, W. Dreier, and J. Piller: Int. J. Thermophys., 2001, vol. 22, pp. 569-78.

14. R.K. Wunderlich and H.-J. Fecht: Meas. Sci. Technol., 2005, vol. 16, pp. 402-16.

15. W.-K. Rhim and K. Ohsaka: J. Cryst. Growth, 2000, vol. 208, pp. 313-21.

16. P.-F. Paradis, T. Ishikawa, T. Aoyama, and S. Yoda: J. Chem. Thermodyn., 2002, vol. 34, pp. 1929-42.

17. J. Lee, J.E. Rodriguez, R.H. Hyers, and D.M. Matson: Met. Mater. Trans. B, published online 14 August 2015. DOI: 10.1007/s11663-014-0178-9.

18. J. Lee and D.M. Matson: Int. J. Thermophys., 2014, vol. 35, pp. 1697-1704.

19. R.K. Wunderlich and H.-J. Fecht: Int. J. Mater. Res., 2011, vol. 102, pp. 1164-73.

20. This calibration experiments were performed at DLR Cologne in the framework of their Microgravity User Support Center (MUSC).

21. Method implemented by Dr. Stephan Schneider, Dr. Marc Engelhardt and Dr. David Heuskin from the German Aerospace Center, DLR Cologne, Institute for Materials Science in Space.

22. J. Etay, P. Schetelat, B. Bardet, J. Priede, V. Bojarevics, and K. Pericleous: High Temp. Mater. Process., 2008, vol. 27, pp. 439-47.

23. R.W. Hyers: Meas. Sci. Technol., 2005, vol. 16, pp. 394-401.

24. G. Lohöfer: Meas. Sci. Technol., 2005, vol. 16, pp. 417-25.

25. G. Lohöfer, G. Pottlacher: High Temp. High Press., 2011, 40, 237-48. 
26. U. Glatzel, T. Mack, S. Woellmer and W. Wortmann: US-Patent US2005254991 A1 2005.

27. G.L. Erickson: JOM, 1995, vol. 47, p. 4.

28. P.N. Quested, R.F. Brooks, L. Chapman, R. Morell, Y. Youssef, and K.C. Mills: Mater. Sci. Technol., 2009, vol. 25, pp. 154-62.

29. Z. Li, K.C. Mills, M. McLean, K. Mukai: Metall. Mater. Trans., 2005, 36B, 247-54.

30. I. Egry, H. Giffard, and S. Schneider: Meas. Sci. Technol., 2005, vol. 16 , pp. $426-31$.

31. S.R. Berry, R.W. Hyers, L.M. Racz, and B. Abedian: Int. J. Thermophys., 2005, vol. 26, pp. 1565-81.

32. H. Fujii, T. Matsumoto, and K. Nogi: Acta Mater., 2000, vol. 48, pp. 2933-39.

33. V. Bojarevics and K. Pericleous: ISIJ Int., 2003, vol. 43, pp. 890-98.

34. Lord. Rayleigh: Proc. R. Soc., 1879, vol. 29, pp. 71-97.

35. D.I. Cummings and D.A. Blackburn: J. Fluid. Mech., 1991, vol. 224 , pp. $395-16$

36. I. Egry, G. Jacobs, J. Schwartz, and J. Szekely: Int. J. Thermophys., 1996, vol. 17, pp. 1181-89.

37. I. Egry, G. Lohöfer, and G. Jacobs: Phys. Rev. Lett., 1995, vol. 75, pp. 4043-45.

38. R. K.Wunderlich and H.-J. Fecht: Int. J. Mat. Res., 2011) 102, 1162-72. Software tool was provided by German Aerospace Center, DLR, Cologne, Microgravity User Support Center.

39. K. Higuchi, M. Watanabe, H.-J. Fecht and R. K. Wunderlich, Proc. Third Int. Symposium on Physical Sciences in Space ISPS 2007, Nara, Japan JASMA, JAXA 367 (2007).

40. K. Higuchi, M. Watanabe, R.K. Wunderlich, and H.-J. Fecht: $J$. Jpn. Soc. Microgr. Appl., 2007, vol. 24, pp. 169-75 (in Japanese).

41. I. Egry, H. Giffard, and S. Schneider: Meas. Sci. Technol., 2005, vol. 16, pp. 426-31.

42. K. Higuchi, H.-J. Fecht, and R.K. Wunderlich: Adv. Eng. Mat., 2007, vol. 9, pp. 349-54.
43. H. Lamb: Hydrodynamincs, Cambridge University Press, Cambridge, 1975, ISBN : 0521055156 -p. 450.

44. J. Etay, P. Schetelat, J. Priede, V. Bojarevics, and K.A. Pericleous: High Temp. Mater. Proc., 2008, vol. 27, pp. 439-47.

45. Z. Li, K.C. Mills, M. McLean, and K. Mukai: Met. Mater. Trans., 2005, vol. 36B, pp. 247-54.

46. E. Ricci, D. Giuranno, R. Novakovic, T. Matsushita, S. Seetharaman, R. Brooks, L.A. Chapman, and P.N. Quested: Int. J. Thermophys., 2007, vol. 28, pp. 1304-21.

47. D. Giuranno, S. Amore, R. Novakovic, and E. Ricci: J. Mater. Sci., 2015, vol. 50, pp. 3763-71.

48. R. Novakovic and E. Ricci, Calphad XXXI, Stockholm, 2002.

49. I. Egry, G. Lohöfer, and S. Sauerland: Int J. Thermophys., 1993, vol. 14 , pp. $573-84$.

50. J. Brillo and I. Egry: J. Mat. Sci., 2005, vol. 40, pp. 2213-16.

51. K. Nogi, W.B. Chung, A. McLean, and W.A. Miller: Mater. Trans. JIM, 1991, vol. 32, pp. 164-68.

52. B.J. Keene, K.C. Mills, and R.F. Brooks: Mater. Sci. Tech., 1985, vol. 1 , pp. $559-67$

53. D. Giuranno, S. Amore, R. Novakovic, and E. Ricci: J. Mater. Sci., 2015, vol. 50, pp. 3763-71.

54. R.F. Brooks, A.P. Day, R.J. Andon, L.A. Chapman, K.C. Mills, and P.N. Quested: High Temp. High Press., 2001, vol. 33, pp. 7382.

55. P.N. Quested, R. Brooks, L.A. Chapman, R. Morrell, Y. Youssef, and K.C. Mills: Mat. Sci. Technol., 2009, vol. 25, pp. 154-62.

56. Y. Sato, K. Sugisawa, D. Aoki, and T. Yamamura: Meas. Sci. Technol., 2005, vol. 16, pp. 363-71.

57. R.F. Brooks, A.P. Day, R.J.L. Andon, L.A. Chapman, K.C. Mills, and P.N. Quested: High Temp. High Press., 2001, vol. 33, pp. $73-82$.

58. K.C. Mills, Y.M. Youssef, and Z. Li: ISIJ Int., 2006, vol. 46, pp. $50-57$. 